\title{
Deformation Law of the Diaphragm Wall during Deep Foundation Pit Construction on Lake and Sea Soft Soil in the Yangtze River Delta
}

\author{
Yuan Mei, ${ }^{1,2}$ Dongbo Zhou $\mathbb{D}^{1,2}$ Xueyan Wang, ${ }^{3}$ Liangjie Zhao, ${ }^{1,2}$ Jinxin Shen, ${ }^{1,2}$ \\ Shumin Zhang, ${ }^{1,2}$ and Yuanying Liu ${ }^{1,2}$ \\ ${ }^{1}$ School of Civil Engineering, Xi'an University of Architecture and Technology, Xi'an 710055, Shaanxi, China \\ ${ }^{2}$ Shaanxi Key Lab of Geotechnical and Underground Space Engineering, Xi'an 710055, Shaanxi, China \\ ${ }^{3}$ School of Urban Planning and Municipal Engineering, Xi'an Polytechnic University, Xi'an 710048, Shaanxi, China \\ Correspondence should be addressed to Dongbo Zhou; zdb@xauat.edu.cn
}

Received 6 November 2020; Revised 15 December 2020; Accepted 24 December 2020; Published 19 January 2021

Academic Editor: Song-He Wang

Copyright (c) 2021 Yuan Mei et al. This is an open access article distributed under the Creative Commons Attribution License, which permits unrestricted use, distribution, and reproduction in any medium, provided the original work is properly cited.

\begin{abstract}
So far, there have been a large number of diaphragm walls in the Yangtze River Delta as engineering examples of deep foundation pit maintenance structures in subway stations, but there is a lack of systematic research and summary on the deformation characteristics of ground connecting walls. This study aimed to clarify the deformation law of the diaphragm wall during the excavation of a deep foundation pit in a soft soil region. Based on the monitoring data of the diaphragm wall of the deep foundation pit of the Hangzhou metro station, the monitoring data of the deep foundation pits of 15 subway stations in Shanghai and Ningbo cities around Hangzhou were considered. Grouping and classification methods were used to analyze the similarities and differences in the deformation characteristics of the diaphragm wall in the three regions. The results indicate the following: the maximum lateral deformation of the diaphragm wall in Hangzhou increases linearly with the relative depth of the maximum lateral deformation. The maximum lateral deformation of the foundation pit in Hangzhou is $0.072 \% \mathrm{H} \sim 0.459 \% \mathrm{H}$, with a mean of $0.173 \% \mathrm{H}$. The wall deformation in Hangzhou varies significantly with the depth of the foundation pit, but the influence of the depth of the foundation pit on the wall deformation is considerably less than that in Shanghai and Ningbo. The corresponding position of the maximum lateral deformation in the excavation depth increases linearly with the excavation depth of the foundation pit, and the corresponding position of the lateral deformation of the diaphragm wall in Shanghai is more affected by the excavation depth of the foundation pit. The lateral deformation of the diaphragm wall increases rapidly in the range of $0 \mathrm{H}-0.5 \mathrm{H}$, and the maximum lateral deformation occurs at $0.5 \mathrm{H}-1.1 \mathrm{H}$.
\end{abstract}

\section{Introduction}

Soft soil has significant structural properties including high compressibility, high water content, high sensitivity, low strength, low permeability, and low bearing capacity [1], resulting in high-risk excavation of the foundation pit in a soft soil region and the occasional occurrence of disastrous foundation pit accidents therein. Soft soil is widely present throughout China's coastal areas, and the rapid economic development and a high degree of urbanization in coastal regions have increased the excavation scale of foundation pits in soft soil areas. Therefore, the special engineering properties of soft soil not only lead to a significant construction risk to the excavation of a foundation pit but also provide a wide space for the optimization design of construction personnel.

Owing to the complexity and uncertainty of the site conditions in the excavation of deep foundation pits, the influence of various factors on deformation cannot be considered simultaneously using the existing theory. The on-site monitoring data embodies the comprehensive effect of various factors in the construction process. Therefore, an indepth analysis of the monitoring data becomes an effective source to understand the deformation characteristics of deep 
excavation in soft soil. However, because monitoring data collection is generally a time-consuming process, and some of the foundation pit monitoring data collection does not meet the requirements of the specifications, the use of limited monitoring data to effectively analyze the deformation law of the foundation pit needs to be studied urgently.

Several studies have been conducted to effectively analyze the deformation law of a deep foundation pit. Clough, Long, Boone, Moormann, and others have statistically analyzed the construction process of foundation pits under different geological conditions worldwide; they investigated the deformation characteristics of various foundation pits by category and obtained the deformation laws of the foundation pit, which have been widely used in foundation pit design and construction [2-5]. I. H. L. Wong, Musuda, Leung, Hsieh, and Pakbaz analyzed and summarized the maximum lateral displacement, settlement, and the maximum deformation position of the foundation pit in Singapore, Japan, Hong Kong, Taipei, Iran, and other regions, respectively, during foundation pit excavation; their proposed rules were widely applied to the engineering practice [6-10]. Wang, Xu, Li, Zhang, Mei, and Elbaz analyzed the deformation characteristics and influencing factors of foundation pits in Shanghai, Beijing, Jinan, Xi'an, Guangzhou, and other regions, respectively; their findings can be used as an effective reference for engineering practice in these regions [11-16]. In addition, Alipour, Farzi, Zhang, Hsieh, and Cui analyzed the deformation laws of representative single foundation pit excavation projects in Tehran, Awaz, Singapore, Taipei, and Nanjing; these results enrich the practice of foundation pit excavation in this region and can be used as a useful supplement for the deformation laws of the foundation pit [17-21].

The studies mentioned above provide an effective reference for the analysis of the foundation pit excavation law in a soft soil region for this study; however, the study of the deformation law of the diaphragm wall regarding the deep excavation of the metro station in the Hangzhou region is still insufficient. This study is based on monitoring data of the deep foundation pit in Hangzhou; 15 subway stations in the cities of Shanghai and Ningbo, which are in the proximity of Hangzhou, are also considered. Grouping and classification methods were used to analyze the similarities and differences in the deformation characteristics of the diaphragm wall in the three regions. The results can provide a reference for the targeted design and construction of the diaphragm wall of a station's deep foundation pit in varying soft soil regions. The improvement of the deformation mechanism of a station's deep foundation pit and design theory and the reduction in construction risk are also significant.

The main soft soil distribution along the coast of China, which is analyzed in this study, is shown in Figure 1.

\section{Overview of Foundation Pit Statistics}

2.1. Geological Conditions. The common characteristics of soft soil, such as significant natural water content, high compressibility, and low strength, make the engineering properties of soft soil poor; the soft soil engineering properties

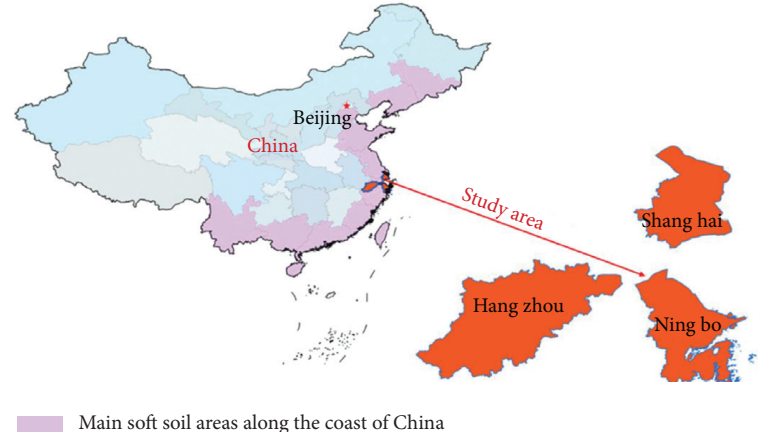

Figure 1: The main soft soil distribution along the coast of China and the soft soil distribution region in this paper.

vary significantly across China, with apparent regional characteristics. All these factors increase the construction risk of the foundation pit excavation of a subway station in a soft soil area. The urban area of Hangzhou is located south of the Yangtze River Delta, the North Bank of the lower reaches of Qiantang River, and the west end of Hangzhou Bay; having a complex landform, the soft soils in the Hangzhou are mainly Quaternary Holocene marine and lacustrine soft soils, of which silt, silty clay, muddy clay, and clay distributed within 2-20 m below the surface are the main soft soil layers affecting project construction. Shanghai is located in the southeast front of the Yangtze River Delta; the soft soil layer is distributed stably in the coastal area, mainly composed of muddy, silty clay and lower muddy clay, and the thickness of the soil layer generally ranges from $10.0 \mathrm{~m}$ to $20.0 \mathrm{~m}$. Ningbo is located south of the Yangtze River Delta; its coastal soft soil is mainly composed of muddy, silty clay and muddy clay, and the typical soft soil thickness is more than $10 \mathrm{~m}$. The physical and mechanical parameters of the soft soil of the three locations are shown in Table 1 [22-25].

2.2. Foundation Pit Overview. To reduce the number of factors influencing foundation pit deformation, the statistical data in this study include all the deep foundation pits of the metro station; the maintenance structure is the diaphragm wall, and the internal support is the form of the reinforced concrete brace + steel brace. The basic information of the station is shown in Table 2. The variables used in this study are shown in Figure 2.

\section{Analysis of Deformation Characteristics of the Foundation Pit}

3.1. Relationship between the Maximum Lateral Deformation and Relative Depth of Maximum Lateral Deformation of the Diaphragm Wall. The maximum lateral deformation of a diaphragm wall is related to the relative depth of the maximum lateral deformation $[9,12]$. Figure 3 indicates the relationship between the maximum lateral deformation $\left(U_{h \max }\right)$ and the relative depth of the maximum lateral deformation $\left(H_{h} / H\right)$ of the diaphragm wall. As shown in Figure 3(a), the relative depth of the lateral deformation of the diaphragm wall in Hangzhou is $0.5-2$, with a mean value 
TABLE 1: Physical and mechanical parameters of soft soil in three places.

\begin{tabular}{|c|c|c|c|c|c|c|c|c|}
\hline Region & Numbering & Soil name & $\begin{array}{c}\text { Distribution } \\
\text { depth }(\mathrm{m})\end{array}$ & $\begin{array}{l}\text { Natural water } \\
\text { content }(\mathrm{w} / \%)\end{array}$ & $\begin{array}{l}\text { Void ratio } \\
(\mathrm{e} 0)\end{array}$ & $\begin{array}{c}\text { Internal friction } \\
\text { angle }\left(\varphi /{ }^{\circ}\right)\end{array}$ & $\begin{array}{c}\text { Cohesion } \\
\text { (c/kpa) }\end{array}$ & $\begin{array}{l}\text { Plasticity } \\
\text { index (ip) }\end{array}$ \\
\hline & 1 & $\begin{array}{l}\text { Muddy clay } \\
\text { layer } \\
\text { Silt, silty clay } \\
\text { layer }\end{array}$ & $\begin{array}{l}6-10 \\
5-8\end{array}$ & $38-58$ & $1.0-1.6$ & $9-15$ & $9-17$ & $13-23$ \\
\hline Hangzhou & 2 & $\begin{array}{l}\text { Muddy clay } \\
\text { layer } \\
\text { Clay and silty } \\
\text { interlayer }\end{array}$ & $\begin{array}{l}2-10 \\
3-4\end{array}$ & $32-46$ & $0.9-1.3$ & $8-18$ & $8-22$ & $10-18$ \\
\hline Shanghai & $\begin{array}{l}3 \\
4\end{array}$ & $\begin{array}{l}\text { Muddy silty clay } \\
\text { Mucky clay }\end{array}$ & $\begin{array}{c}1.8-27 \\
9.0-17.3\end{array}$ & $\begin{array}{c}36-450 \\
40-60\end{array}$ & $\begin{array}{l}1.0-1.4 \\
1.1-1.7\end{array}$ & $\begin{array}{c}12-28 \\
9-17\end{array}$ & $\begin{array}{c}9-14 \\
12-16\end{array}$ & $\begin{array}{l}10-17 \\
17-25\end{array}$ \\
\hline Ningbo & $\begin{array}{l}5 \\
6\end{array}$ & $\begin{array}{l}\text { Muddy silty clay } \\
\text { Mucky clay }\end{array}$ & $\begin{array}{l}3.2-16.4 \\
2.2-16.5\end{array}$ & $\begin{array}{l}34-51 \\
38-58\end{array}$ & $\begin{array}{l}1.0-1.4 \\
1.1-1.5\end{array}$ & $\begin{array}{l}7-28 \\
6-14\end{array}$ & $\begin{array}{l}8-34 \\
8-33\end{array}$ & $\begin{array}{c}9-17 \\
20-24\end{array}$ \\
\hline
\end{tabular}

TABLE 2: Statistics of basic deformation information of the deep foundation pit of the station.

\begin{tabular}{|c|c|c|c|c|c|c|}
\hline \multirow{2}{*}{ Numbering } & \multirow{2}{*}{ Project name } & \multicolumn{3}{|c|}{$\begin{array}{l}\text { Excavation size of the } \\
\text { foundation pit }\end{array}$} & \multirow{2}{*}{$\begin{array}{l}\text { Thickness of the } \\
\text { diaphragm wall (m) }\end{array}$} & \multirow{2}{*}{ Support mode } \\
\hline & & $\begin{array}{l}\text { Length } \\
\text { (m) }\end{array}$ & $\begin{array}{l}\text { Width } \\
(\mathrm{m})\end{array}$ & $\begin{array}{l}\text { Depth } \\
(\mathrm{m})\end{array}$ & & \\
\hline 1 & Fengqi road station [22] & 182.9 & 22.1 & 24.78 & 1.0 & $\mathrm{~N} / \mathrm{A}$ \\
\hline 2 & $\begin{array}{l}\text { Qingchun road Jiangnan well } \\
\text { foundation pit [23] }\end{array}$ & 86.8 & 25.2 & 29 & 1.2 & $\begin{array}{l}6 \text { reinforced concrete } \\
\text { supports }\end{array}$ \\
\hline 3 & $\begin{array}{l}\text { Foundation pit of a station of metro } \\
\qquad \text { line } 2[24,25]\end{array}$ & 245.5 & 24.025 & 17.945 & $1.0 / 1.2$ & $\begin{array}{l}1 \text { concrete support }+5 \text { steel } \\
\text { supports }\end{array}$ \\
\hline 4 & $\begin{array}{l}\text { Foundation pit of a station of metro } \\
\text { line } 5[24,25]\end{array}$ & 182.9 & 25.025 & 25.35 & 1.2 & $\begin{array}{l}3 \text { concrete supports }+4 \\
\text { concrete supports }\end{array}$ \\
\hline 5 & Pengbu road station [26] & 443.9 & 44.5 & 17 & 0.8 & $\begin{array}{c}3 \text { concrete supports }+5 \text { steel } \\
\text { supports }\end{array}$ \\
\hline 6 & Qingnian road station [27] & 200 & 30 & 16.93 & 0.8 & $\begin{array}{c}2 \text { concrete supports }+3 \text { steel } \\
\text { supports }\end{array}$ \\
\hline 7 & Xintang and Jingfang stations [28] & 465.6 & 20.7 & 17 & 0.8 & $\begin{array}{c}1 \text { steel support }+4 \text { concrete } \\
\text { supports }\end{array}$ \\
\hline 8 & Fuming road station [29] & 189 & 18 & 17.16 & 0.8 & $\begin{array}{l}1 \text { concrete support }+4 \text { steel } \\
\text { supports }\end{array}$ \\
\hline 9 & $\begin{array}{l}\text { Deep foundation pit of a station of } \\
\text { Ningbo metro line } 1 \text { [30] }\end{array}$ & 175 & 19.25 & 17.28 & 0.8 & $\begin{array}{c}1 \text { concrete support }+4 \text { steel } \\
\text { supports }\end{array}$ \\
\hline 10 & Minglou station [31] & 154.75 & 24.025 & 17.9 & 0.8 & $\begin{array}{l}1 \text { concrete support }+5 \text { steel } \\
\text { supports }\end{array}$ \\
\hline 11 & $\begin{array}{l}\text { A foundation pit of Shanghai M6 } \\
\text { line [32] }\end{array}$ & 1056.334 & N/A & 16 & $0.6 / 0.8$ & $\begin{array}{c}\text { Two concrete } \\
\text { supports + two steel } \\
\text { supports }\end{array}$ \\
\hline 12 & Gulang station [33] & 420 & 26 & 17.95 & 0.8 & $\begin{array}{c}1 \text { concrete support }+3 \text { steel } \\
\text { supports }\end{array}$ \\
\hline 13 & $\begin{array}{c}\text { Foundation pit of a station in } \\
\text { Shanghai [34] }\end{array}$ & 95 & 25 & 21.5 & 1 & $\begin{array}{l}1 \text { concrete support }+5 \text { steel } \\
\text { supports }\end{array}$ \\
\hline 14 & $\begin{array}{c}\text { Deep foundation pit of a station in } \\
\text { Shanghai [35] }\end{array}$ & 489 & N/A & 21.3 & $0.8 / 1$ & $\begin{array}{l}1 \text { concrete support }+5 \text { steel } \\
\text { supports }\end{array}$ \\
\hline 15 & Qufu road station of line M2 [36] & 288.4 & 20.1 & 23.32 & 1 & $\mathrm{~N} / \mathrm{A}$ \\
\hline
\end{tabular}

Note. N/A means that there are no relevant data in the cited papers, and the data are mainly derived from reports and existing papers.

of 1.46; the greater the relative depth of the maximum lateral deformation, the greater the maximum lateral deformation. There is a linear relationship between the maximum lateral deformation of the diaphragm wall and the relative depth of the maximum lateral deformation. According to previous studies $[28,29]$ and Table 1 , the significant change in the relative depth of the lateral deformation of the diaphragm wall in the Hangzhou region is primarily due to the fact that the characteristics of the soft soil at the bottom of the pit are quite different during the excavation process. When the bottom of the foundation pit consists of moderately compressible soft soil, the relative lateral displacement depth of the diaphragm wall will decrease, and the maximum lateral deformation of the diaphragm wall will also decrease. When 


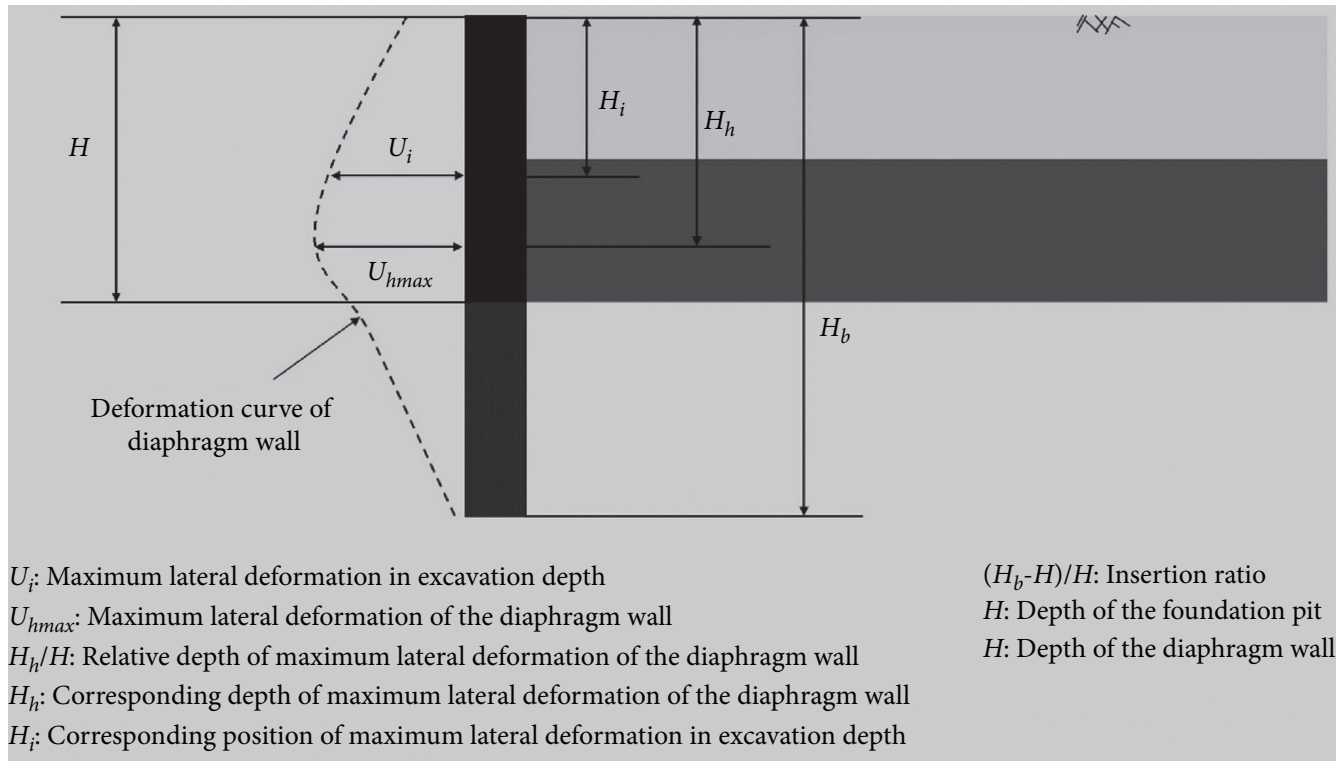

Figure 2: Variable symbols of the foundation pit and their meanings.

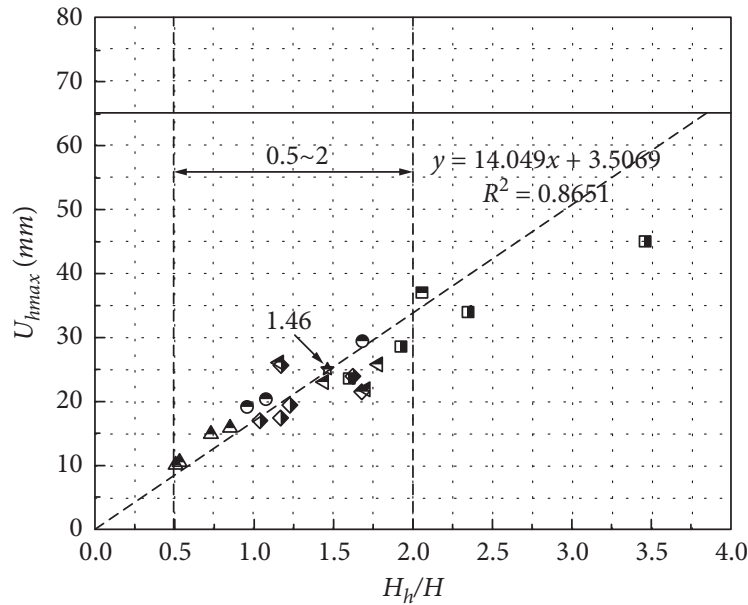

- Fengqi road station

$\triangle$ Foundation pit of a station of metro line 2

$\diamond$ Foundation pit of a station of metro line 5

$\checkmark$ Xintang and Jingfang

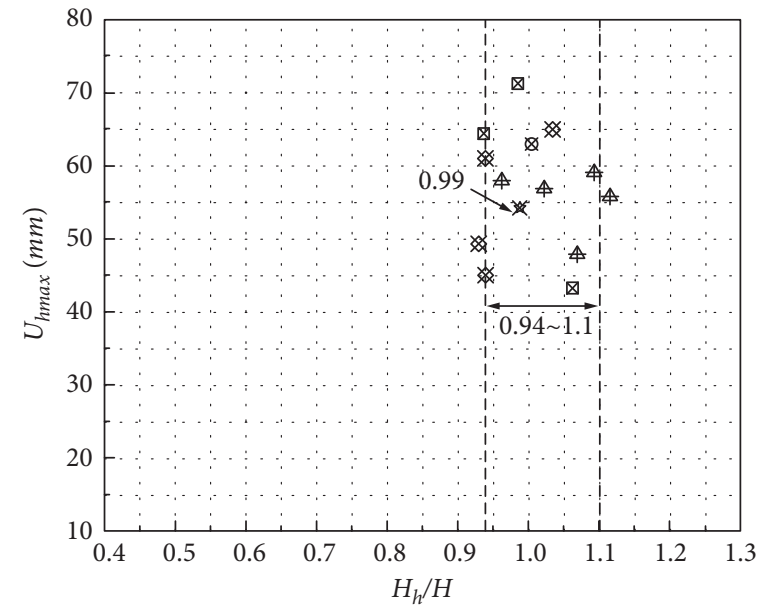

Deep foundation pit of a station in Shanghai

4 Foundation pit of a station in Shanghai

A A foundation pit of Shanghai M6 line

* Gulang station

* Mean value

Figure 3: Continued. 


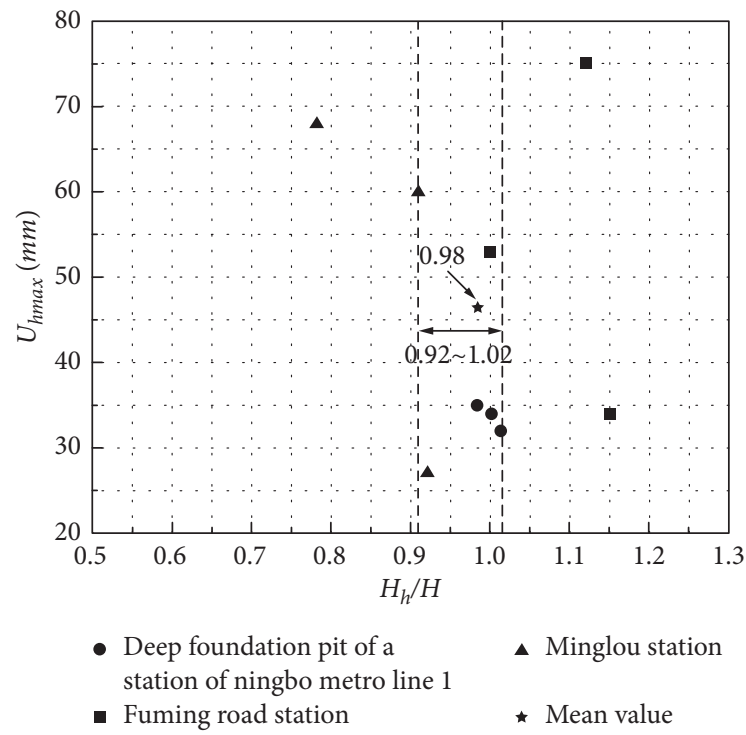

(c)

FIGURE 3: Relationship between the maximum lateral deformation and the relative depth of the maximum lateral deformation of the diaphragm wall. (a) Hangzhou. (b) Shanghai. (c) Ningbo.

the bottom of the foundation pit consists of high compression soft soil, the relative lateral deformation of the diaphragm wall will increase, and the corresponding lateral deformation of the diaphragm wall will also increase. Therefore, in order to reduce the lateral deformation of the diaphragm wall, the soil at the bottom of the pit can be properly reinforced by mixing piles and cast-in-place piles to increase the strength of the soil [26].

As shown in Figures 3(b) and 3(c), the relative depth of the lateral deformation of the diaphragm wall in Ningbo is $0.92-1.02$, with a mean of 0.98 ; the relative depth of the lateral deformation of the diaphragm wall in Shanghai is $0.94-1.1$, with a mean of 0.99 . The relative depth of the maximum lateral deformation of the diaphragm wall in the two locations changes insignificantly, mainly because the soft soil properties at the bottom of the two pits do not change significantly; most of the foundation pit bottom is reinforced $[35,36]$, which also makes the maximum lateral deformation relative depth of the diaphragm wall in the two locations smaller than that in Hangzhou.

\subsection{Influence of the Insertion Ratio on the Maximum Lateral} Deformation of the Diaphragm Wall. The insertion ratio of the diaphragm wall (the ratio of the embedded depth below the foundation pit bottom of the ground connection wall to the depth of the foundation pit) is an important factor affecting the excavation deformation of the foundation pit. In general, when the wall has sufficient strength and rigidity, the degree of deformation of the foundation pit can be effectively reduced and the coefficient of stability against the uplift of the soil can be improved by appropriately increasing the insertion ratio [15]. Figure 4 presents the relationship between the insertion ratio of the diaphragm wall and the maximum lateral deformation of the diaphragm wall.
As shown in Figure 4, the maximum lateral deformation of the diaphragm wall decreases with an increase in the insertion ratio. As shown in Figure 4(a), the insertion ratio of the diaphragm connection wall in Hangzhou is apparently 0.73-1.1, with a mean value of 0.95 ; excluding the anomalous data of Group 1, the insertion ratio in Hangzhou has a clear linear relationship with the maximum lateral deformation of the diaphragm wall. As shown in Figure 4(b), the insertion ratio of the diaphragm wall in Shanghai is $0.81-1.02$, with a mean value of 0.93 ; the insertion ratio of Shanghai also has a linear relationship with the maximum lateral deformation of the diaphragm wall, but the correlation during a linear fitting for the coefficient $R^{2}$ is excessively small. This is mainly because the statistical sample in Shanghai is small; therefore, there is an accidental error in data fitting, but it has the same deformation trend as Hangzhou. No apparent rules have been found in Ningbo owing to insufficient data. Considering the analysis above, if the maximum lateral deformation of the diaphragm wall is too large in actual projects, it can be limited by appropriately increasing the insertion ratio of the diaphragm wall.

\subsection{Influence of the Aspect Ratio on the Maximum Lateral} Deformation of the Diaphragm Wall. Studies have shown [15] that the aspect ratio of foundation pit excavation has a significant effect on the stability of the foundation pit. Figure 5 presents the relationship between the aspect ratio of the foundation pit and the lateral deformation of the diaphragm wall.

The maximum lateral deformation of the diaphragm wall increases with the increase of aspect ratio of the foundation pit, as shown in Figure 5. However, the correlation coefficient between the two is apparently not large; in addition, the effect of the ratio of the length to the width on the lateral shape of the diaphragm wall is not clear and requires further study. 


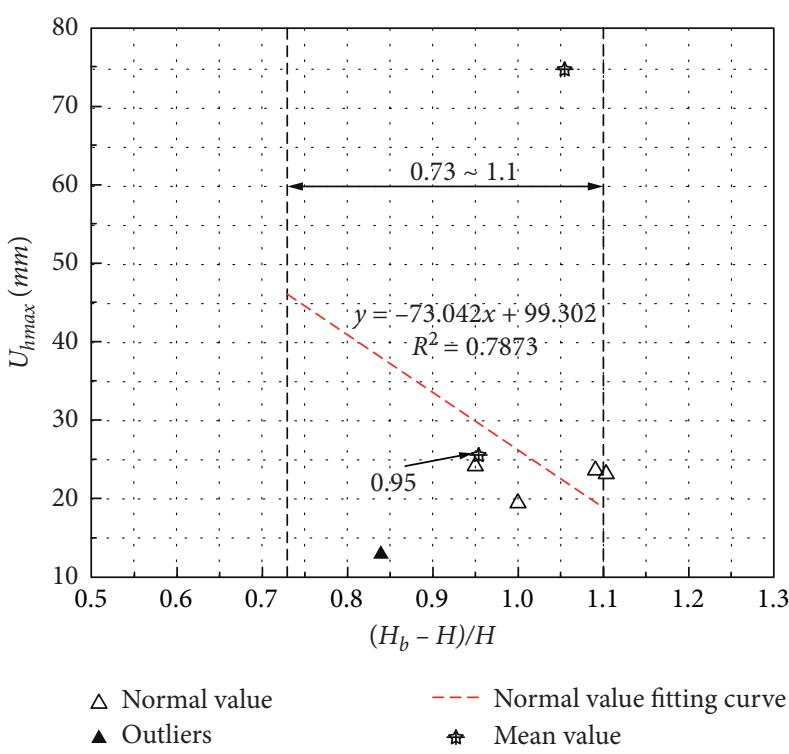

(a)

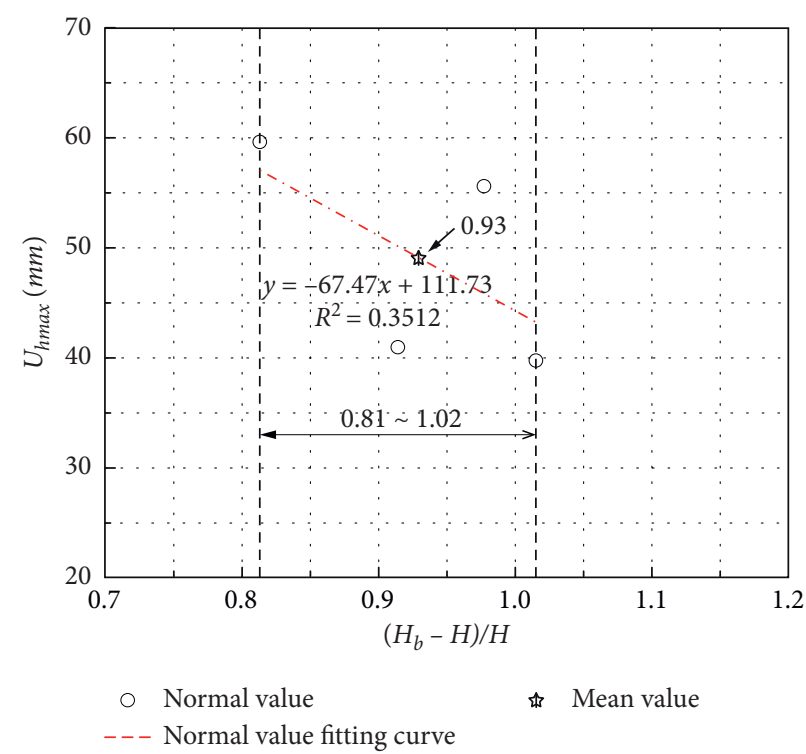

(b)

FIGURE 4: Relationship between insertion ratio and maximum lateral deformation of the foundation pit. (a) Hangzhou. (b) Shanghai.

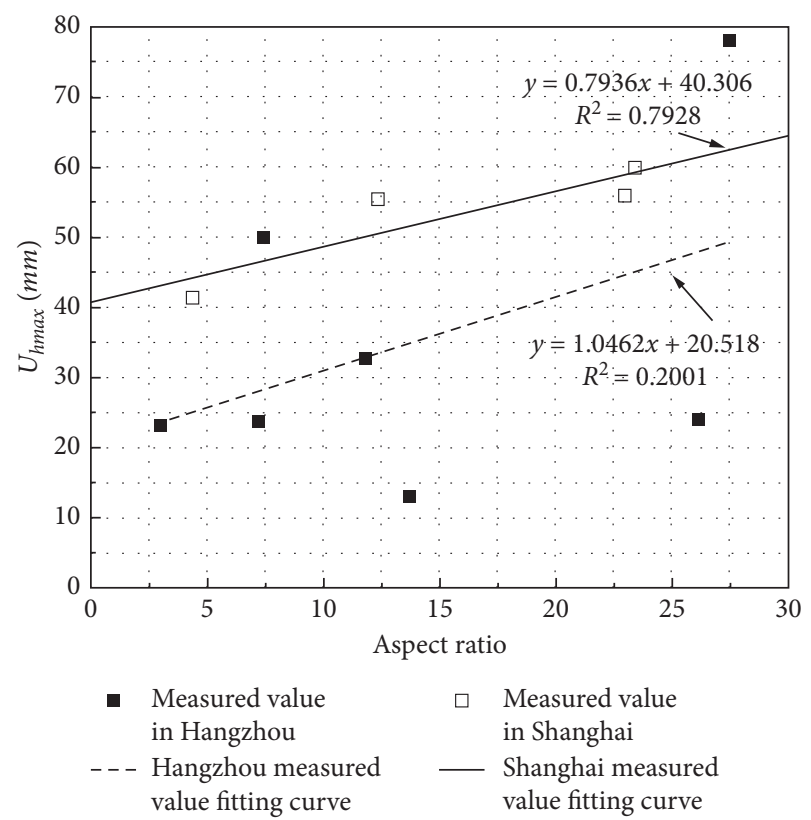

FIgURE 5: Relationship between aspect ratio and maximum lateral deformation of the wall.

However, the basic trend of the aspect ratio regarding the lateral deformation of the wall is similar to that reported in $[13,15]$.

\subsection{Relationship between the Depth of the Foundation Pit and} the Maximum Lateral Deformation of the Wall. The relationship between the maximum lateral deformation of the wall and the depth of the foundation pit is shown in Figure 6; the maximum lateral deformation of the wall increases with the increase of the depth of the foundation pit. The maximum lateral deformation of the foundation pit in Hangzhou is $0.072 \% \mathrm{H} \sim 0.459 \% \mathrm{H}$, with a mean value of $0.173 \% \mathrm{H}$, and that in Shanghai is $0.171 \% \mathrm{H} \sim 0.373 \% \mathrm{H}$, with a mean value of $0.258 \% \mathrm{H}$, similar to the statistical laws of Xu Zhonghua and Yang Min. The maximum lateral deformation of the foundation pit in Ningbo is $0.195 \% \mathrm{H} \sim 0.327 \% \mathrm{H}$, with a mean value of $0.270 \% \mathrm{H}$.

Considering the comparison, the wall deformation in Hangzhou varies significantly with the depth of the foundation pit, but the influence of the depth of the foundation pit on the wall deformation is far less than that in Shanghai and Ningbo; the wall in Shanghai and Ningbo is substantially affected by the depth of the foundation pit. As shown in Table 2, there are more types of soft soil in Hangzhou than in the other two locations. Hence the variation of the influence of the foundation pit excavation on the diaphragm wall is significant, which is an important reason why the wall deformation in Hangzhou varies widely with the depth of the foundation pit. Therefore, Shanghai and Ningbo should pay attention to the influence of the depth of the foundation pit on the deformation of the walls of the two places during the construction process; reducing the lateral deformation of the wall by increasing the internal support can be considered [37]. Hangzhou can consider reducing the internal support density to improve the engineering economy on the premise of ensuring safety.

Based on the aforementioned analysis, to compare the deformation performance of the support system under different excavation conditions, the statistical data regarding the lateral deformation of the support in other regions are summarized in Table 3.

The results indicate that the relationship between the maximum lateral deformation of the wall in Hangzhou and the depth of the foundation pit is similar to that in Tokyo, and the relationship between the maximum lateral deformation and the depth of the foundation pit in Shanghai and 


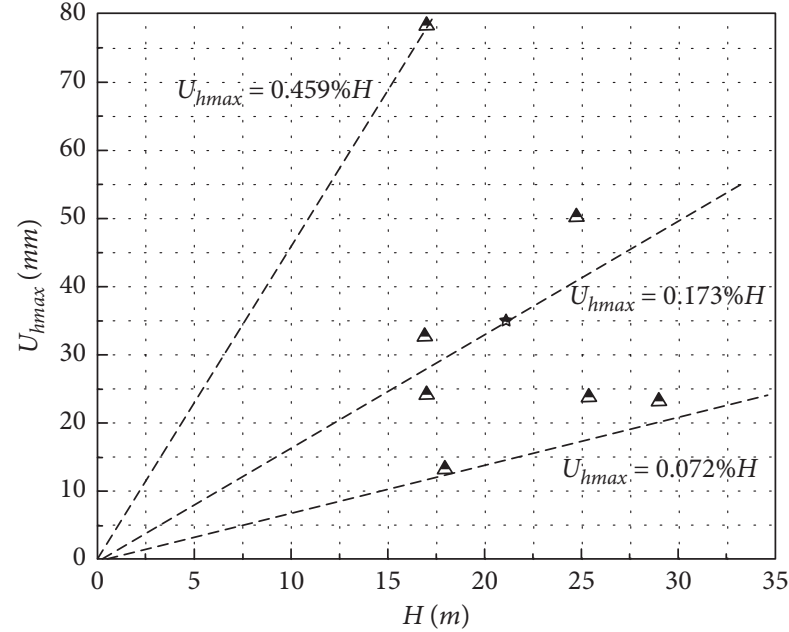

$\Delta$ Measured value

* Mean value

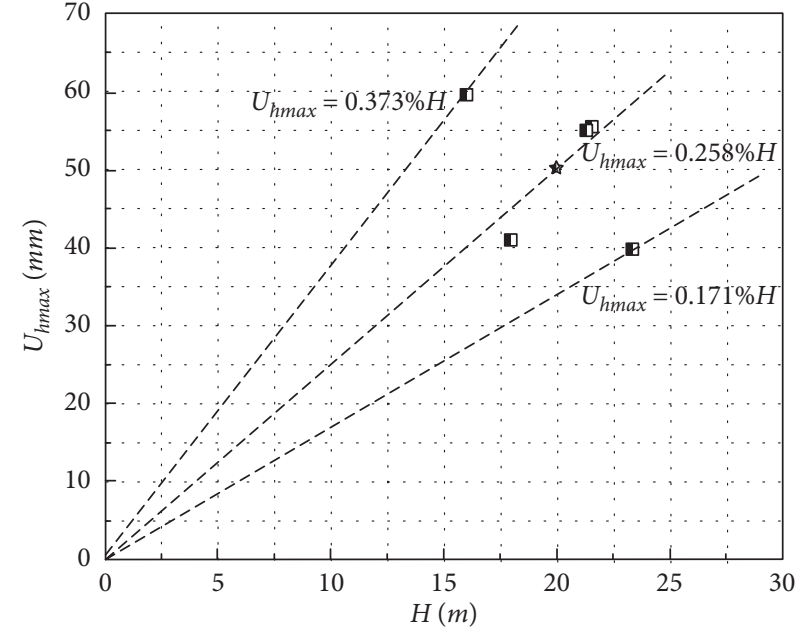

- Measured value

» Mean value

(a)

(b)

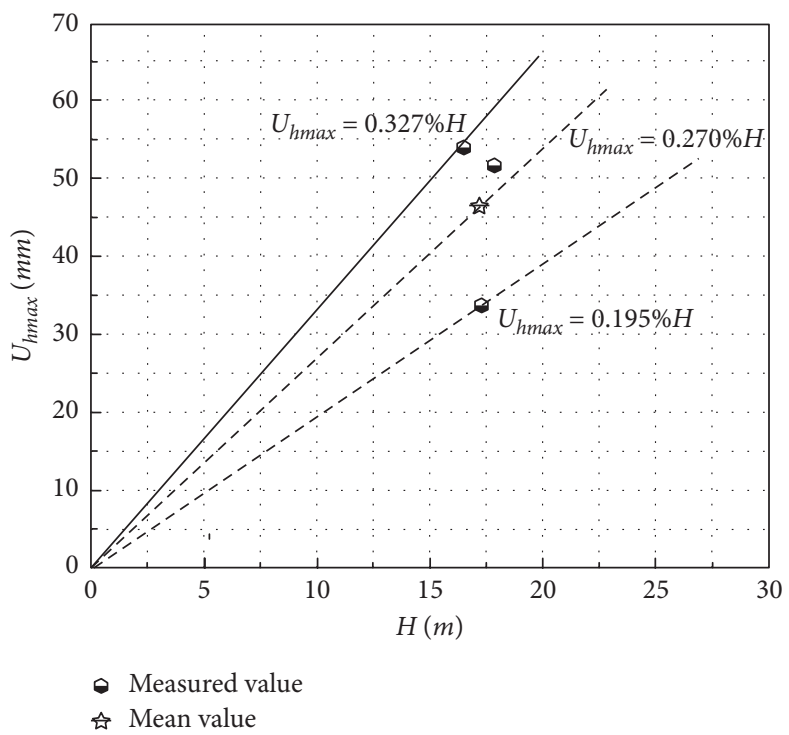

(c)

Figure 6: Relationship between the depth of the foundation pit and the maximum lateral deformation of the wall. (a) Hangzhou. (b) Shanghai. (c) Ningbo.

Ningbo is similar to that of Taipei; however, the change range is smaller than that of Taipei.

The lateral deformation of the foundation pits in Singapore, Dublin, Hong Kong, Guangzhou, Jinan, and other regions is relatively small, owing to the nature of the soil layer and the construction technique. The foundation pits in Singapore and Jinan were constructed in soft soil, but the support system used bored pile or sheet pile support. The bored pile or sheet pile support structure is believed to have stronger constraints on the lateral deformation of the wall; hence, when the lateral deformation of the wall exceeds the specification, the drilling pile strength, sheet pile support, or combined support can be considered.
3.5. Relationship between the Excavation Depth and the Corresponding Position of the Maximum Lateral Deformation within the Excavation Depth. As shown in Figure 7, the greater the excavation depth, the deeper the position corresponding to the maximum lateral deformation. There is an apparent linear relationship between the excavation depth and the position corresponding to the maximum lateral deformation within the excavation depth. The corresponding position depth of the lateral deformation of the diaphragm wall in Shanghai is more affected by the excavation depth of the foundation pit. According to the statistical law $[2,13]$, the lateral deformation of the diaphragm wall is generally "bow-shaped" during the 
TABLE 3: Comparison of wall lateral deformation with other areas.

\begin{tabular}{|c|c|c|c|c|}
\hline Numbering & Location & Ground condition & Support form & $\begin{array}{c}U_{\text {hmax }}(\mathrm{H}) \\
(\%)\end{array}$ \\
\hline OU [9] & Taipei & Silty sand and silty clay & Diaphragm wall and sheet piles & $0.2-0.5$ \\
\hline Masuda [7] & Tokyo & Sand and clay & Diaphragm wall & $0.05-0.5$ \\
\hline Wong [6] & Singapore & Stiff clay & $\begin{array}{c}\text { Contiguous bored pile and diaphragm } \\
\text { wall }\end{array}$ & $0.03-0.2$ \\
\hline Long [3] & $\begin{array}{l}\text { Dublin- } \\
\text { Jervis }\end{array}$ & Glacial till & Soldier piles and sheet piles & $0.07-0.2$ \\
\hline Leung [8] & Hong Kong & $\begin{array}{l}\text { Successive layers of fill, marine deposit, and } \\
\text { decomposed geomaterials }\end{array}$ & Diaphragm wall & $0.09-0.29$ \\
\hline Zhang [38] & Jinan & Jinan soft clay & $\begin{array}{c}\text { Concrete piles, jet grouting columns, } \\
\text { and anchors }\end{array}$ & $0.02-0.19$ \\
\hline Elbaz [16] & Guangzhou & Sand covered karst & Diaphragm wall & $0.08-0.3$ \\
\hline
\end{tabular}

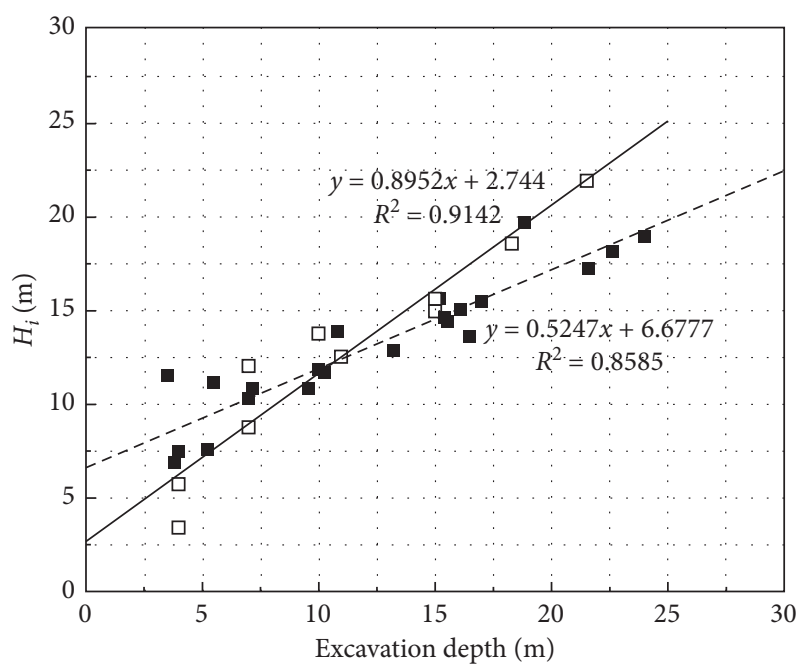

- Measured value in Hangzhou

- - - Hangzhou measured value fitting curve

$\square \quad$ Measured value in Shanghai

_ Shanghai measured value fitting curve

Figure 7: The relationship between the excavation depth and the corresponding position of the maximum lateral deformation within the excavation depth.

excavation of the foundation pit. Hence the soil at the maximum lateral deformation of the diaphragm wall will not suddenly reach 0 . The excavation of the foundation pit in Shanghai has a wider influence on the diaphragm wall and soil because the corresponding depth of the diaphragm wall is more affected by the excavation depth of the foundation pit. When the excavation depth of the soft soil foundation pit in Shanghai gradually increases, the influence of the soil excavation on the diaphragm wall and the lateral deformation of soil should be considered during the design and construction.

3.6. Relationship between Excavation Depth and Maximum Lateral Deformation within Excavation Depth. Figure 8 presents the trend line of the relationship between the excavation depth and the maximum lateral deformation within the excavation depth; during the excavation of the two foundation pits, as the excavation depth increases, the maximum lateral deformation of the wall in the excavation depth continues to increase, but the deformation rules of the two are different. When the excavation depth of the foundation pit is shallow in Shanghai, the maximum lateral deformation of the diaphragm wall is relatively large. The maximum lateral deformation rate of the diaphragm wall gradually decreases as the excavation depth increases, corresponding to the slope of the fitting curve gradually decreasing in Shanghai. When the excavation of the foundation pit is shallow in Hangzhou, the maximum lateral deformation of the diaphragm wall is small. The maximum lateral deformation rate of the diaphragm wall gradually increases as the excavation depth increases, corresponding to the slope of the fitting curve in Hangzhou gradually increasing. Considering the maximum lateral deformation law of the diaphragm wall during the excavation of the two locations, the wall deformation at the initial stage of the foundation pit excavation in Shanghai should be focused on; increasing the top layer of the internal support to reduce the influence of the larger wall deformation in the early stage can be considered. Hangzhou should focus on the influence of the increase in the wall deformation rate deeper in the excavation of the foundation pit. The deformation law can be appropriately used by considering a small initial deformation and fast deformation rate in the later period by reducing the upper support density and increasing the lower support density.

3.7. Lateral Deformation Mode of the Wall. Figure 9 presents the statistical distribution curve of the horizontal lateral displacement along with the wall depth when the diaphragm wall is excavated to the bottom of the pit; the wall deformation changes into a "bow" distribution mode being large in the middle and small at both ends, which is similar to the law summarized in $[2,13]$. There is a small range of change for the diaphragm wall in Hangzhou, but that in Shanghai and Ningbo is large, with an insignificant difference between them. A small number of foundation pits have negative lateral displacement values at the top of the wall, generally within $5 \mathrm{~mm}$, which is mainly due to the excessive axial force of the first support or the outward thrust of a gantry crane erected on the crown beam. 


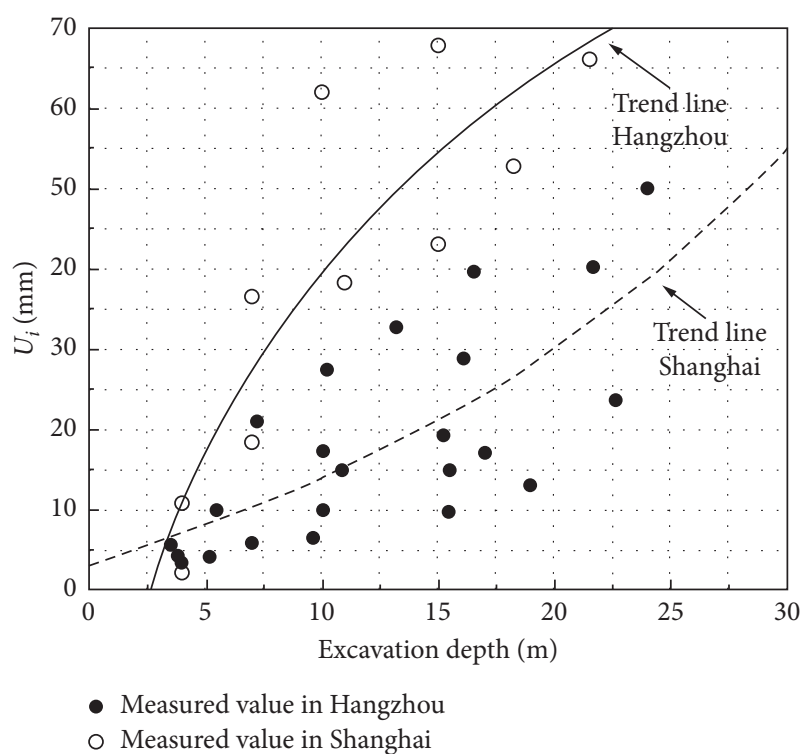

FIgURE 8: Relationship between excavation depth and maximum lateral deformation within excavation depth.

In order to further analyze the wall lateral deformation mode, the lateral deformation curve is considered dimensionless, for which the horizontal axis is the ratio of the lateral displacement to the maximum lateral displacement, and the vertical axis is the ratio of the excavation depth to the foundation pit depth. The results are shown in Figure 10.

As shown in Figure 10, although the construction and soil conditions, as well as the construction methods for each foundation pit, are quite different, the upper and lower limits of a $95 \%$ confidence interval of the dimensionless cubic polynomial can well envelope the deformation curve of the foundation pit, which is similar to the results of the dimensional analysis conducted by Li Shu [13]. The lateral displacement of the diaphragm wall increases rapidly in the range of $0 \mathrm{H}-0.5 \mathrm{H}$, and the maximum lateral displacement occurs at a position between $0.5 \mathrm{H}-1.1 \mathrm{H}$. The maximum lateral displacement of a diaphragm wall decreases gently in the range of $1.1 \mathrm{H}-2.0 \mathrm{H}$. After $2.0 \mathrm{H}$, the lateral displacement of the diaphragm wall is negligible. The analysis apparently indicates that the foundation pit must be supported in a timely manner in the early stage due to the rapid growth of the diaphragm wall lateral displacement. When the foundation pit is excavated to half of the depth of the foundation pit, the lateral deformation of the wall essentially reaches its maximum value; strict monitoring should be performed to prevent construction safety problems due to the deformation of the foundation pit exceeding the specified limit.

\section{Discussion}

The manuscript systematically compares and analyzes the lateral deformation modes of the Diaphragm wall during the excavation of the soft soil foundation pits of subway stations in different regions of the Yangtze River Delta and points out the differences between their changes. At the same time, the influence of the aspect ratio and the insertion ratio on the deformation characteristics of the ground wall is analyzed.

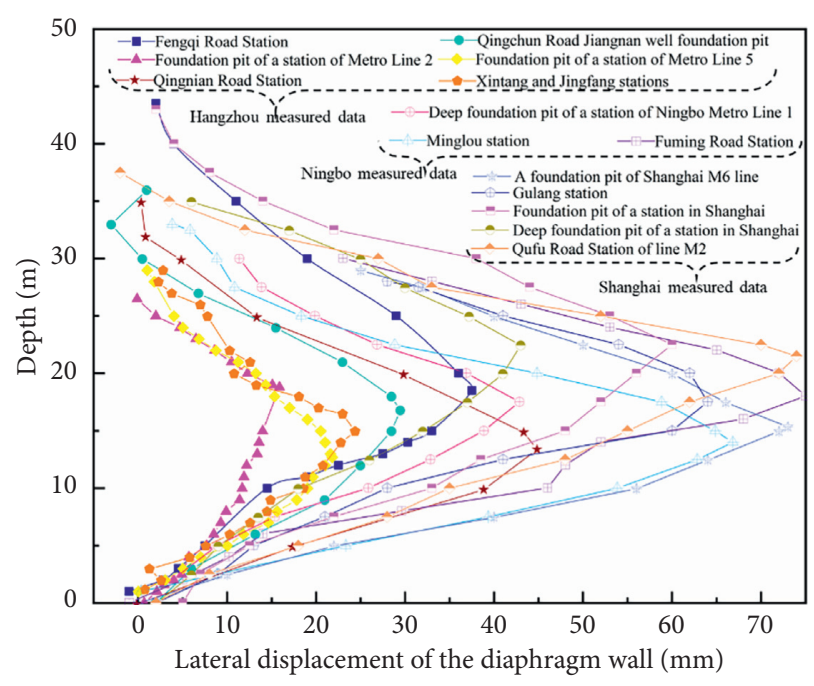

Figure 9: The measured curve of the lateral deformation of the wall.

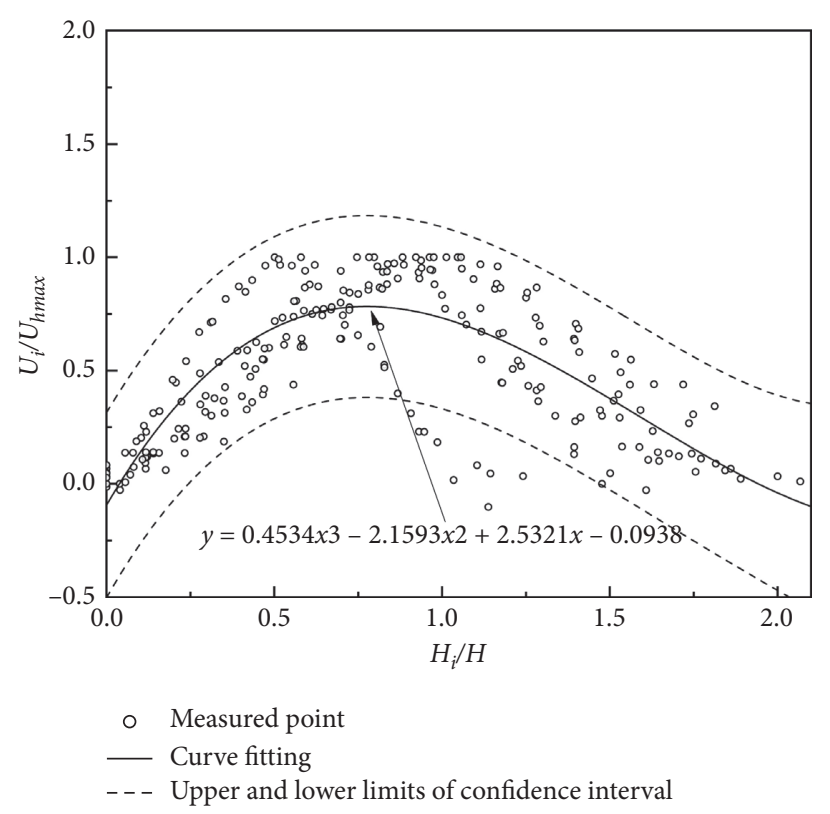

FIgURE 10: Dimensionless treatment of the lateral deformation mode of the wall.

This provides a reference for guiding the optimization of the excavation design plan and construction plan of the subway station foundation pit in different soft soil areas of the Yangtze River Delta. However, the manuscript is limited by the limited statistical data of Ningbo soft soil area, and it is not comprehensive enough to summarize the deformation characteristics of the ground wall in the Ningbo. The content needs to be improved with the development of engineering construction in Ningbo.

\section{Conclusion}

(i) The corresponding position of the maximum lateral deformation in the excavation depth increases 
linearly with the increase of the excavation depth of the foundation pit.

(ii) When the excavation depth of the foundation pit is shallow in Shanghai, the maximum lateral deformation value of the diaphragm wall is larger, and the maximum lateral deformation rate of the diaphragm wall gradually decreases with the increase of the excavation depth. However, the relationship between the maximum lateral deformation value and the deformation rate with depth during the excavation of the diaphragm wall in Hangzhou is opposite to that in the Shanghai area.

(iii) The lateral deformation of the diaphragm wall increases rapidly in the range of $0 \mathrm{H}-0.5 \mathrm{H}$, and the maximum lateral deformation occurs in the range of $0.5 \mathrm{H}-1.1 \mathrm{H}$. During construction in this range, it is necessary to strengthen monitoring to prevent safety problems caused by the deformation of the foundation pit exceeding the standard value.

\section{Data Availability}

The data used to support the findings of this study are available from the first author upon request.

\section{Conflicts of Interest}

The authors declare that there are no conflicts of interest regarding the publication of this paper.

\section{Acknowledgments}

This work was supported by the Key Research and Development Project of Shaanxi Province (Grant no. 2020SF-373) and the Special Research Project of Shaanxi Provincial Education Department (Grant no. 19JK0381).

\section{References}

[1] R. Chen, F. Meng, Z. Li, Y. Ye, and J. Ye, "Investigation of response of metro tunnels due to adjacent large excavation and protective measures in soft soils," Tunnelling and Underground Space Technology, vol. 58, pp. 224-235, 2016.

[2] G. Clough and W. Orourketd, "Construction Induced movements of in situ walls," in Proceedings of the ASCE Conference on Design and Performance of Earth Retaining Structures Special Publication No.25, pp. 439-470, ASCE, New York, NY, USA, June 1990.

[3] M. Long, "Database for retaining wall and ground movements due to deep excavations," Journal of Geotechnical and Geoenvironmental Engineering, vol. 127, no. 3, pp. 203-224, 2001.

[4] S. J. Boone, "Analysis of wall and ground movements due to deep excavations in soft soil based on a new worldwide database," Soils and Foundations, vol. 45, no. 4, pp. 165-166, 2005.

[5] C. Moormann, "Analysis of wall and ground movements due to deep excavations in soft soil based on a new worldwide database," Soils and Foundations, vol. 44, no. 1, pp. 87-98, 2004.

[6] I. H. Wong, T. Y. Poh, and H. L. Chuah, "Performance of excavations for depressed expressway in Singapore," Journal of Geotechnical and Geoenvironmental Engineering, vol. 123, no. 7, pp. 617-625, 1997.

[7] T. Masuda, Behavior of Deep Excavation with Diaphragm Wall, Massachusetts Institute of Technology, Cambridge, MA, USA, 1993.

[8] E. H. Y. Leung, W. Charles and W. Ng, "Wall and ground movements associated with deep excavations supported by cast in situ wall in mixed ground conditions," Journal of Geotechnical and Geoenvironmental Engineering, vol. 133, no. 2, pp. 129-143, 2007.

[9] C.-Y. Ou, P.-G. Hsieh, and D.-C. Chiou, "Characteristics of ground surface settlement during excavation," Canadian Geotechnical Journal, vol. 30, no. 5, pp. 758-767, 1993.

[10] M. S. Pakbaz, S. Imanzadeh, and K. H. Bagherinia, "Characteristics of diaphragm wall lateral deformations and ground surface settlements: case study in Iran-Ahwaz metro," Tunnelling and Underground Space Technology, vol. 35, pp. 109121, 2013.

[11] Z. W. Wang, C. W. Ng, and G. B. Liu, "Characteristics of wall deflections and ground surface settlements in Shanghai," Canadian Geotechnical Journal, vol. 42, no. 5, pp. 1243-1254, 2005.

[12] J. H. Wang, Z. H. Xu, and W. D. Wang, "Wall and ground movements due to deep excavations in shanghai soft soils," Journal of Geotechnical and Geoenvironmental Engineering, vol. 136, no. 7, pp. 985-994, 2010.

[13] S. Li, D. Zhang, Q. Fang et al., "Research on characteristics of retaining wall deformation due to deep excavation in Beijing," Chinese Journal of Rock Mechanics and Engineering, vol. 31, no. 11 , pp. 2344-2353, 2012, in chinese.

[14] Z. Ding-Wen, S. Ji-Cheng, S. Jian-Ping et al., "Observed deformation characteristics of a deep excavation for the spring area in Jinan, China," Journal of Mountain Science, vol. 14, no. 3, pp. 581-594, 2017.

[15] Y. Mei, X.-Y. Li, J. Wang, and C.-M. Hu, "Statistical analysis of deformation laws of deep foundation pits in collapsible loess," Arabian Journal for Science and Engineering, vol. 44, no. 10, pp. 8347-8360, 2019.

[16] K. Elbaz, S.-L. Shen, Y. Tan, and W.-C. Cheng, "Investigation into performance of deep excavation in sand covered karst: a case report," Soils and Foundations, vol. 58, no. 4, pp. 1042-1058, 2018.

[17] A. Alipour and A. Eslami, "Design adaptations in a large and deep urban excavation: case study," Journal of Rock Mechanics and Geotechnical Engineering, vol. 11, no. 2, pp. 389-399, 2019.

[18] M. Farzi, M. S. Pakbaz, and H. A. Aminpour, "Selection of support system for urban deep excavations: a case study in Ahvaz geology," Case Studies in Construction Materials, vol. 8, pp. 131-138, 2018.

[19] W. G. Zhang, H. Li, Y. Q. Li et al., "Effects of jet grouting slabs on responses for deep braced excavations," Underground Space, 2020.

[20] P.-G. Hsieh and C.-Y. Ou, "Mechanism of buttress walls in restraining the wall deflection caused by deep excavation," Tunnelling and Underground Space Technology, vol. 82, pp. 542-553, 2018.

[21] X. Cui, M. Ye, and Y. Zhuang, "Performance of a foundation pit supported by bored piles and steel struts: a case study," Soils and Foundations, vol. 58, no. 4, pp. 1016-1027, 2018.

[22] X. G. Li, Theoretical Study on Stabilization of Marine Soft Clay in Hangzhou, Zhejiang University, Zhejiang, China, 2013, in chinese.

[23] X. G. Li, R. Q. Xu, X. C. Wang et al., "Assessment of engineering properties for marine and lacustrine soft soil in 
Hangzhou," Journal of Zhejiang University (Engineering Science), vol. 47, no. 8, pp. 1346-1352, 2013, in chinese.

[24] X. M. Zhou, L. Y. Yuan, J. Q. Cai, and X. J. Hou, "Analysis of soft soil distributional characteristics and deformation examples of Shanghai area," Shanghai Geology, no. 4, pp. 6-9, 2005, in chinese.

[25] S.-L. Shen, H.-N. Wu, Y.-J. Cui, and Z.-Y. Yin, "Long-term settlement behaviour of metro tunnels in the soft deposits of shanghai," Tunnelling and Underground Space Technology, vol. 40, pp. 309-323, 2014.

[26] N. W. Liu, Y. T. Chen, and J. T. Yu, "Analysis of deformation characteristics of foundation pit of metro station and adjacent buildings induced by deep excavation in soft soil," Rock and Soil Mechanics, vol. 40, no. 4, pp. 1515-1525, 2019, in chinese.

[27] X. C. Zhang, X. N. Gong, X. Y. Yin, and Y. B. Zhao, "Monitoring analysis of retaining structures for Jiangnan foundation pit of Qingchun road river-crossing tunnel in Hangzhou," Rock and Soil Mechanics, vol. 32, no. S1, pp. 488-494, 2011, in chinese.

[28] B. Xu, Z. Wang, G. Wei, C. J. Shi, and L. F. Xu, "Analysis of deformation and force monitoring of deep foundation pit in Jianguo Road Station of Hangzhou Metro," in Proceedings of the 2016 China Tunnel and Underground Engineering Conference, no. 9, Chengdu, China, August 2016, in chinese.

[29] B. Xu, Analysis on Effect of Deep Foundation Pit Excavation of Metro Station in Soft Soil Area of Hangzhou, Zhejiang University of Technology, Zhejiang, China, 2016, in chinese.

[30] C. Lei, "Analysis of calculation and monitoring results of foundation pit of Pengbu station of Hangzhou metro," Railway Standard Design, no. 5, pp. 79-83, 2011, in chinese.

[31] J. G. Wang, G. J. Jing, J. Xu, and Y. J. Yao, "Construction monitoring and analysis of Youth road metro station in Hangzhou," Soil Engineering and Foundation, vol. 33, no. 2, pp. 116-120, 2019, in chinese.

[32] Z. Ding, D. Wang, X. F. Yu, J. Y. Wang, and J. Q. Jiang, "Monitoring and analysis of deep foundation pit at Xintang Road-Jingfang Road cross of Hangzhou metro," Chinese Journal of Geotechnical Engineering, vol. 35, no. S2, pp. 445-451, 2013, in chinese.

[33] J. N. Ye, "Dynamic monitoring and numerical simulation of foundation excavation of second stage work for Fuming road station," Chinese Journal of Underground Space and Engineering, vol. 8, no. S1, pp. 1517-1526, 2012, in chinese.

[34] Z. H. Hu and S. D. Zhu, "Study on deformation characteristics of diaphragm wall in deep foundation pit of Ningbo metro stations," Modern Urban Transit, no. 5, pp. 38-41, 2018, in chinese.

[35] B. Wu, Y. Y. Peng, and S. Q. Pu, "Analysis on time-space effect of excavation construction of adjacent deep foundation pit in Ningbo soft soil area," Journal of Railway Science and Engineering, vol. 17, no. 1, pp. 82-94, 2020, in chinese.

[36] Y. Liu, G. B. Liu, X. L. Sun, and H. P. Wang, "Analysis of deformation laws by using the rule of time-space effect in soft soil excavation," Chinese Journal of Geotechnical Engineering, no. S1, pp. 1433-1436, 2006, in chinese.

[37] Y. H. Yang and J. G. Wu, "Analysis of retaining structures for deep foundation pit of Qiutao road station in Hangzhou metro," Chinese Journal of Rock Mechanics and Engineering, no. S2, pp. 3386-3392, 2008, in chinese.

[38] Y. S. Zhang, X. C. Xue, H. Y. Zhuang, and X. Z. Liu, "Effects of soft soil layer on the ground settlement of a long-narrow deep excavated foundation pit for subway station," Chinese Journal of Underground Space and Engineering, vol. 14, no. 6, pp. 1639-1651, 2018, in chinese. 